\title{
Covalently Crosslinked 1,2,4-Triazolium-Containing Polyester Networks Prepared by Michael Addition Polymerization
}

\section{Andreah T. De La Hoz and Kevin M. Miller*}

1201 Jesse D. Jones Hall

Department of Chemistry

Murray State University

Murray, KY 42071

* Corresponding author: Tel.: +1 270809 3543; fax: +1 2708096474

E-mail address: kmiller38@murraystate.edu (K. M. Miller)

\begin{abstract}
:
Michael addition polymerization was used to generate a series of 1,2,4-triazolium-based covalently crosslinked polyester networks. Within the series, the acetoacetate to acrylate ratio as well as the counteranion were varied in an attempt to correlate structural changes with the thermal and mechanical properties of the corresponding networks. An increase in acrylate concentration, as expected, led to an increase in the apparent crosslink density $\rho_{x}$ as well as glass transition temperature $\left(T_{g}\right)$, thermal stability $\left(T_{d 5 \%}\right)$ and rubbery plateau storage modulus $\left(E^{\prime}\right)$. Use of larger, non-coordinating anions such as triflate [OTf] and bis(trifluoromethylsulfonyl)imide [ $\mathrm{NTf}_{2}$ ] led to a decrease in $T_{g}$ and $E^{\prime}$ but an increase in the thermal stability $\left(T_{d 5 \%}>295{ }^{\circ} \mathrm{C}\right)$. Overall, the thermal and mechanical properties of the $1,2,4$ triazolium-containing network, at an acrylate to acetoacetate ratio of 1.4:1.0, were found to be on par with the analogous imidazolium-based network.
\end{abstract}

Keywords: polymerizable ionic liquid, 1,2,4-triazolium, Michael addition 


\section{Graphical Abstract:}

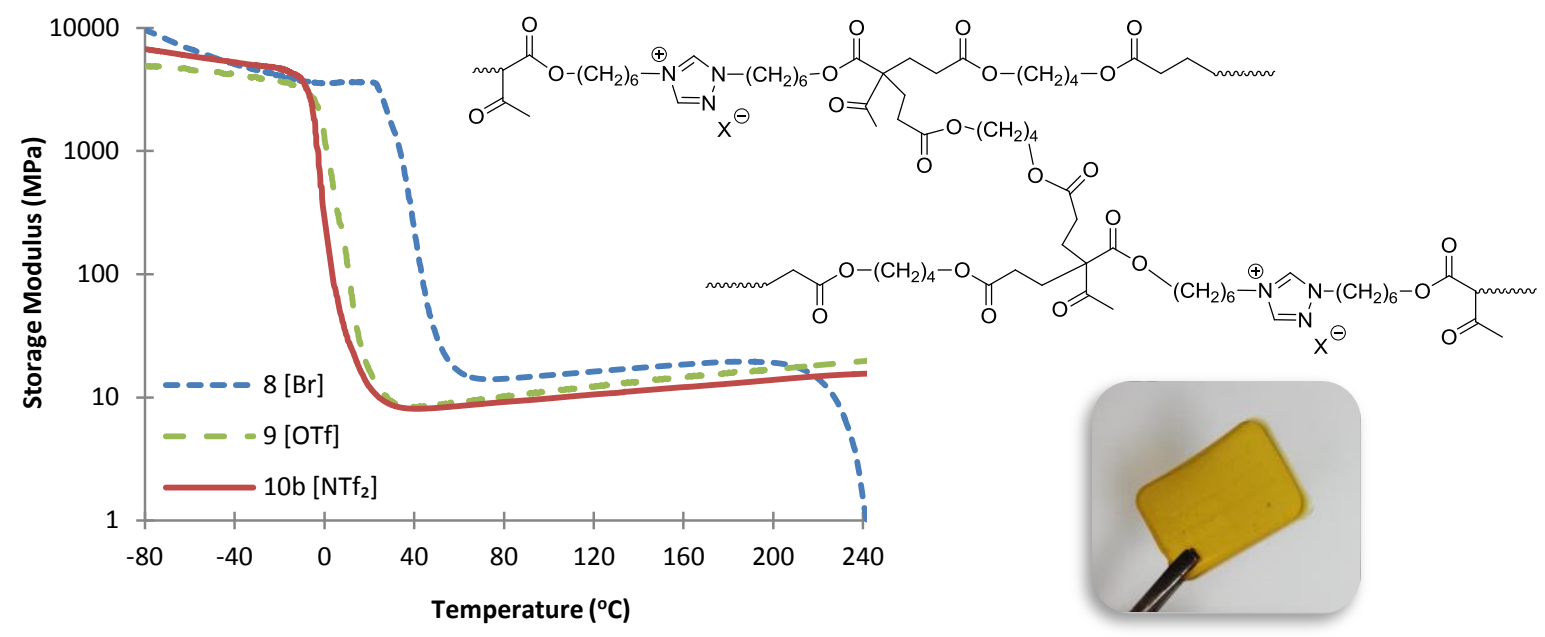




\section{Introduction}

Ionic liquids (ILs) are classically defined as poorly coordinated cation-anion pairs that exhibit a melting point below $100{ }^{\circ} \mathrm{C}$. Research in the field of ILs continues to expand due to the tunable physicochemical properties and wide electrochemical window that stems from the large number of cation-anion combinations available [1-4]. While common IL cations include tetraalkylammonium, tetraalkyphosphonium, $N$-pyridinium and $N, N^{\prime}$-dialkylimidazolium, anions are much more numerous, ranging from halides $([\mathrm{Cl}],[\mathrm{Br}],[\mathrm{I}])$ and fluorinated inorganics $\left(\left[\mathrm{BF}_{4}\right],\left[\mathrm{PF}_{6}\right]\right)$ to bulkier, hydrophobic organics ([OTf $\left.],\left[\mathrm{NTf}_{2}\right]\right)$.

The development of polymerizable ionic liquids (PILs) or poly(ionic liquid)s has opened the door to an even wider range of prospective applications $[5,6]$. PILs are a specific type of IL that contains a polymerizable group, thus allowing for the cationic or anionic center to be constrained within the repeating unit of a polymer chain. PILs have gained a great deal of momentum in polymer and materials science over the last 15 years due to the potential for combining the unique physical, electrochemical and thermal characteristics of ILs with the thermal and mechanical properties of a variety of macromolecular architectures [7-11]. A few representative applications that have been targeted from PIL research include electromechanical devices [12-14], gas separation and carbon dioxide absorption membranes $[15,16]$ and even stabilizers for silver, gold and nickel nanoparticles [17].

Of all the PILs that have been researched, those containing the imidazolium cation have provided the greatest utility insofar as their synthetic versatility is concerned. In many cases, imidazolium-containing polymers have been found to exhibit improved electrochemical and thermal properties when compared to non-ionic analogs $[7-8,11]$. While the imidazolium cation remains a standard for many PILs and their applications, there exists a need to explore other cations in order to provide more flexibility with regards to specific application requirements. For example, 1,2,3- and 1,2,4-triazolium ionic liquids have gained recent interest for potential use in 'energy-rich applications' due to the increased nitrogen content in the ring and the large, positive heats of formation $[18,19]$.

Shreeve has reviewed the physical properties of a number of 'energetic' ionic liquids which employed the 1,2,3- or 1,2,4-triazolium cation in combination with high energy anions such as perchlorate or nitrate [20-23]. In general, the ionic liquids had good thermal stability, 
high densities (> $1.50 \mathrm{~g} / \mathrm{mL}$ ) and high combustion energies. Rogers has also recently highlighted the use of triazolium-containing ionic liquids as hypergolic fuels [24]. Studies in our laboratories have focused on the physicochemical and thermal properties of 1-alkyl-4-methyl1,2,4-triazolium ionic liquids where the $N-1$ alkyl side chain and/or anion was varied [25-27]. All of the ILs were found to exhibit temperature-dependent properties (viscosity, conductivity, density) similar to their imidazolium analogs, however they were less thermally stable.

Despite the promising properties of triazolium-containing ionic liquids, reports concerning PILs containing these cations have been sparse. Polymers containing the 1,2,3triazole group have become significantly easier to access due to the versatility of the coppercatalyzed azide-alkyne (CuAAC) 'click' reaction [28-31]. From this cyclization concept, 1,2,3triazolium-based polymers have been prepared using either a post-quaternization approach or through direct polymerization of 1-vinyl-1,2,3-triazolium PILs [32,33]. Step-growth architectures containing 1,2,3-triazolium ionic liquids have also been explored by Drockemuller [34-36]. In these cases, an $\alpha$-azido- $\omega$-alkyne monomer was subjected to $\mathrm{CuAAC}$ polyaddition followed by quaternization and anion exchange to gain access to a wide variety of 1,2,3triazolium-containing polymers. Of these 1,2,3-triazolium-based polymers, one was found to exhibit ionic conductivity and thermal stability comparable to analogous side-chain PILs [35].

Polymers containing the 1,2,4-triazolium ring have been far less studied. In 2008, Shreeve reported the preparation of chain growth polymers based upon PILs containing the 1,2,4-triazolium ring [37]. Polymers were prepared either by post-quaternization and anion exchange of poly(1-vinyl-1,2,4-triazole)s or direct free radical polymerization of the corresponding 1,2,4-triazolium monomer. These novel 'energetic' polymers were found to exhibit higher densities and improved thermal stabilities than the corresponding monomers.

The present study attempts to explore the structure-activity relationships of a series of covalently crosslinked polyester networks containing a polymerizable 1,2,4-triazoliumcontaining ionic liquid. In order to achieve the desired covalently crosslinked network, Michael addition polymerization was employed [38-40]. In short, the Michael addition, as a polymerization technique, typically consists of a base-catalyzed reaction between a Michael donor such as an diacetoacetate and an $\alpha, \beta$-unsaturated carbonyl compound such as an diacrylate ester (Michael acceptor). Once the acetoacetate is deprotonated, the resulting enolate anion undergoes a 1,4-conjugate addition to the activated olefin, resulting in a new enolate anion, 
which is quickly protonated to regenerate the base catalyst (Scheme 1). Each acetoacetate still contains an acidic proton however $\left(p \mathrm{~K}_{\mathrm{a}} \sim 13\right)$ and thus, in the presence of excess diacrylate, a second Michael addition will occur, resulting in covalent crosslinking between polyester chains. Michael addition polymerization is an attractive alternative to conventional polyester synthesis due to the relatively mild reaction conditions and the lack of removable byproducts.

Additionally, the degree of crosslinking can be easily controlled and uniform molecular weights between crosslink points can be achieved through manipulation of the acrylate to acetoacetate ratio [39].

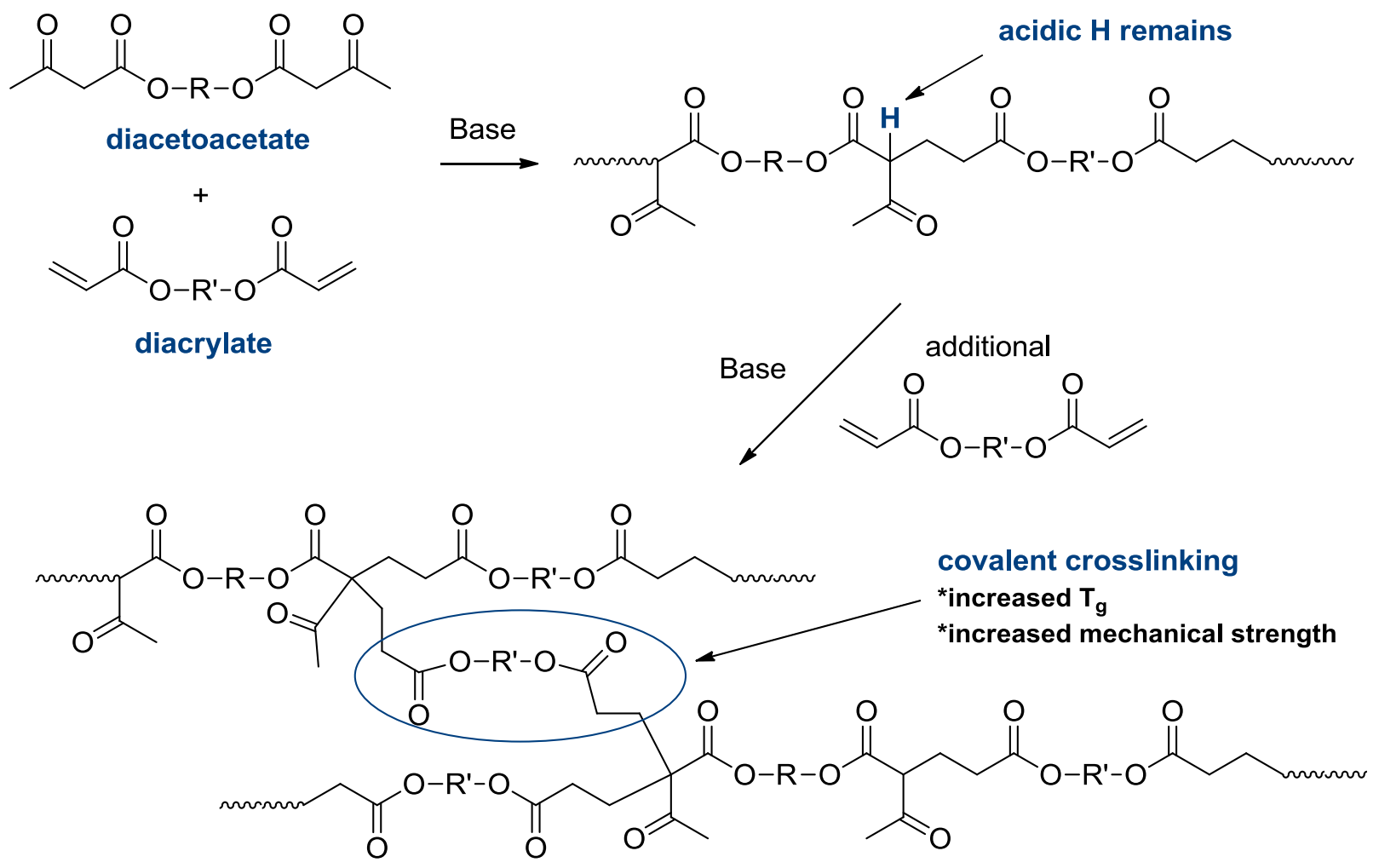

Scheme 1: Covalent Crosslinking Using Michael Addition Polymerization

Our laboratories have recently shown the utility of the Michael addition in the preparation of imidazolium-containing covalently crosslinked networks where the polymerizable IL moiety was incorporated either in sequence or pendant to the polymer backbone $[41,42]$. In these studies, a number of structural variations (backbone alkyl chain length, counteranion) were investigated and correlations with thermal properties such as glass transition temperature $\left(T_{g}\right)$ 
and thermal stability $\left(T_{d 5 \%}\right)$ were discussed. In short, the $T_{g}$ of the polymer networks could be easily controlled through manipulation of the imidazolium-containing acetoacetate monomer, the nature of the counteranion and/or the acrylate concentration. The highest thermal stabilities $\left(T_{d 5 \%}\right)$ were observed when bulky, non-coordinating counteranions such as trifluoromethylsulfonate [OTf] or bis(trifluoromethylsulfonyl)imide [ $\left.\mathrm{NTf}_{2}\right]$ were employed.

As part of the present study, two structural variations of the covalently crosslinked, 1,2,4triazolium-containing polyester networks were investigated: the acrylate to acetoacetate ratio (apparent crosslink density) and counteranion (ionic coordination). The thermal and mechanical properties of the corresponding networks as they relate to these structural deviations are discussed. To the best of our knowledge, this study represents the first report of a step-growth polymer prepared from a 1,2,4-triazolium PIL.

\section{Experimental}

\subsection{Materials}

Ethyl-6-bromohexanoate (Acros, $98 \%$ ), 1,2,4-triazole (Acros, $99 \%$ ), sodium methoxide (5.4 M solution in methanol, Acros), lithium aluminum hydride (Alfa Aesar, $95 \%$ ), tertbutylacetoacetate (Aldrich, 98\%), silver trifluoromethanesulfonate (Acros Organics, 99+ \%), lithium bis(trifluoromethylsulfonyl)imide (Acros Organics, 99\%), 1,4-butanediol diacrylate (Alfa Aesar, 99+\%, stabilized with 50-105 ppm hydroquinone), 1,8-diazabicyclo[5.4.0]undec-7-ene (DBU, Acros, 98\%), ethyl ether (BDH Aristar®, 99.9\%), toluene (Pharmco-AAPER, Reagent Grade ACS), and chloroform (Pharmco-AAPER, Reagent Grade ACS) were used without any further purification. Tetrahydrofuran (THF) (99.9\%) was purchased as anhydrous from Acros Organics and used as received. An ELGA Purelab ${ }^{\circledR}$ Ultra filtration device produced ultrapure water having a resistivity of $18 \mathrm{M} \Omega-\mathrm{cm} .{ }^{1} \mathrm{H}$ and ${ }^{13} \mathrm{C}$ NMR spectra were obtained on a JEOLECS $400 \mathrm{MHz}$ spectrometer and chemical shift values reported below were referenced to residual solvent signals $\left(\mathrm{CDCl}_{3}:{ }^{1} \mathrm{H}, 7.26 \mathrm{ppm} ;{ }^{13} \mathrm{C}, 77.16 \mathrm{ppm}\right.$; DMSO- $d_{6}:{ }^{1} \mathrm{H}, 2.50 \mathrm{ppm} ;{ }^{13} \mathrm{C}$, $39.52 \mathrm{ppm})$. Elemental analyses were completed by Atlantic Microlab, Inc.

\subsection{Synthesis of methyl ester 1}

To a 50-mL round-bottomed flask was dissolved 1,2,4-triazole $(2.00 \mathrm{~g}, 29.0 \mathrm{mmol})$ in anhydrous methanol (25 mL). Sodium methoxide solution (5.4 M in methanol, 5.4 mL, 29.2 
mmol) was added and the resulting solution was allowed to stir at room temperature for 60 minutes. Ethyl-6-bromohexanoate $(6.40 \mathrm{~g}, 28.7 \mathrm{mmol})$ was then added and the resulting stirred solution was warmed to $60{ }^{\circ} \mathrm{C}$ and held for 24 hours. The reaction was then concentrated under reduced pressure to afford a mixture, which was taken up into ethyl ether $(40 \mathrm{~mL})$ and filtered. The solvent was removed under reduced pressure to afford a light yellow oil. The crude oil was purified using high vacuum distillation $\left(142-145^{\circ} \mathrm{C}, 1.0 \mathrm{~mm} \mathrm{Hg}\right)$ to afford $5.21 \mathrm{~g}$ of a clear, colorless oil (92\%). ${ }^{1} \mathrm{H}$ NMR $\left(\mathrm{CDCl}_{3}\right): \delta 1.24(\mathrm{~m}, 3 \mathrm{H}), 1.58(\mathrm{~m}, 2 \mathrm{H}), 1.82(\mathrm{~m}, 2 \mathrm{H}), 2.24(\mathrm{t}, 2$ $\mathrm{H}), 3.57(\mathrm{~s}, 3 \mathrm{H}), 4.10(\mathrm{t}, 2 \mathrm{H}), 7.85(\mathrm{~s}, 1 \mathrm{H}), 8.00(\mathrm{~s}, 1 \mathrm{H}) .{ }^{13} \mathrm{C} \mathrm{NMR}\left(\mathrm{CDCl}_{3}\right): \delta 23.99,25.68$, 29.24, 33.45, 49.18, 51.39, 142.72, 151.66, 173.61. Anal. calculated for $\mathrm{C}_{9} \mathrm{H}_{15} \mathrm{~N}_{3} \mathrm{O}_{2}, \mathrm{C} 54.81, \mathrm{H}$ 7.67, N 21.30; found, C 54.08, H 7.60, N 21.13.

\subsection{Synthesis of 1-(6'-hydroxyhexyl)-1,2,4-triazole 2}

To a 1-liter round-bottomed flask equipped with a magnetic stir bar and a nitrogen inlet was charged lithium aluminum hydride $(2.12 \mathrm{~g}, 55.8 \mathrm{mmol})$ and anhydrous THF $(50 \mathrm{~mL})$. The stirred suspension was cooled to $0{ }^{\circ} \mathrm{C}$ and a solution of methyl ester $1(13.75 \mathrm{~g}, 69.7 \mathrm{mmol})$ in anhydrous THF (200 mL) was added dropwise over a 60 minute period. After the addition was completed, the mixture was allowed to warm to room temperature and stir for 90 minutes, followed by careful quenching with $1.0 \mathrm{M} \mathrm{HCl}$. The mixture was then filtered and the solvent was removed under reduced pressure to afford a clear, colorless liquid, which was further purified by high vacuum distillation $\left(160-163{ }^{\circ} \mathrm{C}, 1.0 \mathrm{~mm} \mathrm{Hg}\right)$, resulting in $9.87 \mathrm{~g}$ of a clear, colorless oil (83\%). ${ }^{1} \mathrm{H}$ NMR (DMSO-d $): \delta 1.19(\mathrm{~m}, 2 \mathrm{H}), 1.28$ (m, $\left.2 \mathrm{H}\right), 1.38(\mathrm{~m}, 2 \mathrm{H}), 1.75$ $(\mathrm{m}, 2 \mathrm{H}), 3.35(\mathrm{t}, J=5.3 \mathrm{~Hz}, 2 \mathrm{H}), 4.15(\mathrm{t}, J=7.1 \mathrm{~Hz}, 2 \mathrm{H}), 4.34$ (t, $1 \mathrm{H},-\mathrm{OH}), 7.94$ (s, $1 \mathrm{H}, \mathrm{Ar}-$ $\left.\mathrm{H}^{3}\right), 8.50\left(\mathrm{~s}, 1 \mathrm{H}, \mathrm{Ar}-\mathrm{H}^{5}\right) .{ }^{13} \mathrm{C} \mathrm{NMR}\left(\mathrm{DMSO}-d_{6}\right): \delta 24.86,25.75,29.36,32.32,48.53,60.57$, 143.84, 151.30. Anal. calculated for $\mathrm{C}_{8} \mathrm{H}_{15} \mathrm{~N}_{3} \mathrm{O}, \mathrm{C} 56.78, \mathrm{H}$ 8.93, N 24.83; found, C 56.62, H 8.92, N 24.62.

\subsection{Synthesis of 1-(6'-acetoacetoxyhexyl)-1,2,4-triazole 3}

To a $250 \mathrm{~mL}$ round-bottomed flask equipped with a magnetic stir bar was dissolved 1-(6'hydroxylhexyl)-1,2,4-triazole $2(5.00 \mathrm{~g}, 29.4 \mathrm{mmol})$ in toluene $(70 \mathrm{~mL})$. To this stirred solution was added tert-butylacetoacetate $(18.63 \mathrm{~g}, 117.8 \mathrm{mmol})$ and the resulting stirred solution was warmed to reflux and held for 2 hours. A simple distillation apparatus was then assembled and 
the toluene/tert-butanol azeotrope was distilled, followed by removal of solvent and excess tertbutylacetatoacetate under reduced pressure. The reaction afforded $6.95 \mathrm{~g}(93 \%)$ of a light orange oil. ${ }^{1} \mathrm{H}$ NMR (DMSO- $\left.d_{6}\right): \delta 1.21(\mathrm{~m}, 2 \mathrm{H}), 1.27(\mathrm{~m}, 2 \mathrm{H}), 1.54(\mathrm{~m}, 2 \mathrm{H}), 1.76(\mathrm{~m}, 2 \mathrm{H})$, 2.18 (s, $3 \mathrm{H}, \mathrm{CH}_{3}$ on AcAc group), 3.59 (s, $2 \mathrm{H}, \mathrm{CH}_{2}$ on AcAc group), 4.02 (t, $2 \mathrm{H}, J=6.6 \mathrm{~Hz}$ ), $4.16(\mathrm{t}, 2 \mathrm{H}, J=7.1 \mathrm{~Hz}), 7.94\left(\mathrm{~s}, 1 \mathrm{H}, \mathrm{Ar}-\mathrm{H}^{3}\right), 8.50\left(\mathrm{~s}, 1 \mathrm{H}, \mathrm{Ar}-\mathrm{H}^{5}\right) .{ }^{13} \mathrm{C}$ NMR (DMSO- $\left.d_{6}\right): \delta$ 24.65, 25.35, 27.81, 29.09, 30.09, 48.43, 49.55, 64.29, 143.91, 151.30, 167.30, 201.61. Anal. calculated for $\mathrm{C}_{12} \mathrm{H}_{19} \mathrm{~N}_{3} \mathrm{O}_{3}, \mathrm{C} 56.90, \mathrm{H}$ 7.56, N 16.59; found, C 56.61, H 7.47, N 16.32.

\subsection{Synthesis of 1-acetoacetoxy-6-bromohexane 4}

The preparation of 6-bromohexan-1-ol has been previously reported [43]. To a 100-mL round-bottomed flask was dissolved 6-bromohexan-1-ol (2.00 g, $11.0 \mathrm{mmol})$ in toluene (20 mL). To this stirred solution was added tert-butylacetoacetate $(3.49 \mathrm{~g}, 22.0 \mathrm{mmol})$. The resulting stirred solution was warmed to reflux and held for 2 hours, followed by simple distillation to remove the toluene/tert-butanol azeotrope. The remaining solvent and excess tertbutylacetoacetate was then removed under reduced pressure to afford a light yellow oil (2.79 $\mathrm{g}$, $95 \%) .{ }^{1} \mathrm{H} \mathrm{NMR}\left(\mathrm{CDCl}_{3}\right): \delta 1.36(\mathrm{~m}, 2 \mathrm{H}), 1.44(\mathrm{~m}, 2 \mathrm{H}), 1.64(\mathrm{~m}, 2 \mathrm{H}), 1.85(\mathrm{~m}, 2 \mathrm{H}), 2.26$ (s, 3 $\mathrm{H}, \mathrm{CH}_{3}$ on AcAc group), 3.39 (t, $2 \mathrm{H}, J=6.9 \mathrm{~Hz}$ ), 3.45 (s, $2 \mathrm{H}, \mathrm{CH}_{2}$ on AcAc group), 4.12 (t, 2 $\mathrm{H}, J=6.6 \mathrm{~Hz}) .{ }^{13} \mathrm{C} \mathrm{NMR}\left(\mathrm{CDCl}_{3}\right): \delta 25.10,27.73,28.42,30.37,32.67,33.81,50.23,65.37$, 167.29, 200.68. Anal. calculated for $\mathrm{C}_{10} \mathrm{H}_{17} \mathrm{BrO}_{3}, \mathrm{C} 45.30$, H 6.46; found, C 45.50, H 6.34.

\subsection{Synthesis of 1,4-bis(6'-acetoacetoxyhexyl)-1,2,4-triazolium bromide 5}

To a $15 \mathrm{~mL}$ round-bottomed flask equipped with a magnetic stir bar was charged 1-(6'acetoacetoxyhexyl)-1,2,4-triazole 3 (1.00 g, $3.94 \mathrm{mmol})$ and 1-acetoacetoxy-6-bromohexane 4 (1.04 g, $3.94 \mathrm{mmol})$. The solution was warmed to $60{ }^{\circ} \mathrm{C}$ and held for 6 days under an atmosphere of nitrogen. The solution was then cooled to room temperature and vigorously washed with several portions of ethyl ether $(4 \times 20 \mathrm{~mL})$. The product was then dried under vacuum at room temperature, resulting in $1.76 \mathrm{~g}$ of a light orange oil $(86 \%)$. ${ }^{1} \mathrm{H}$ NMR (DMSO- $\left.d_{6}\right): \delta 1.32(\mathrm{~m}, 4$ $\mathrm{H}), 1.55(\mathrm{~m}, 4 \mathrm{H}), 1.85(\mathrm{~m}, 4 \mathrm{H}), 2.17\left(\mathrm{~s}, 6 \mathrm{H}, \mathrm{CH}_{3}\right.$ on AcAc group), 3.59 (s, $4 \mathrm{H}, \mathrm{CH}_{2}$ on AcAc group), $4.05(\mathrm{~m}, 4 \mathrm{H}), 4.24(\mathrm{t}, 2 \mathrm{H}, J=6.7 \mathrm{~Hz}), 4.36(\mathrm{t}, 2 \mathrm{H}, J=6.8 \mathrm{~Hz}), 9.26(\mathrm{~s}, 1 \mathrm{H}), 10.20$ (s,

$1 \mathrm{H}) .{ }^{13} \mathrm{C}$ NMR (DMSO- $\left.d_{6}\right): \delta 24.61,25.02,25.04,27.76,27.90,28.64,30.13,47.39,49.61$, 
51.51, 64.24, 142.38, 144.66, 167.32, 201.69. Anal. calculated for $\mathrm{C}_{22} \mathrm{H}_{36} \mathrm{~N}_{3} \mathrm{O}_{6} \mathrm{Br}, \mathrm{C} 50.97, \mathrm{H}$ 7.00, N 8.11; found, C 50.53, H 7.05, N 7.97.

\subsection{Synthesis of 1,4-bis(6'-acetoacetoxyhexyl)-1,2,4-triazolium triflate 6}

To a $50 \mathrm{~mL}$ round-bottomed flask equipped with a magnetic stir bar was dissolved 1,3bis(6'-acetoacetoxyhexyl)imidazolium bromide $5(1.39 \mathrm{~g}, 2.67 \mathrm{mmol})$ in DI water $(15 \mathrm{~mL})$. To this stirred solution was added a solution of silver trifluoromethanesulfonate $(0.70 \mathrm{~g}, 2.72 \mathrm{mmol})$ in deionized water $(5 \mathrm{~mL})$. The mixture was vigorously stirred overnight at room temperature then filtered. The reaction was then extracted with ethyl acetate $(3 \times 20 \mathrm{~mL})$. The organic phases were combined and the solvent was removed under reduced pressure to afford $1.46 \mathrm{~g}(92 \%)$ of a light yellow oil. ${ }^{1} \mathrm{H}$ NMR (DMSO- $\left.d_{6}\right): \delta 1.31(\mathrm{~m}, 4 \mathrm{H}), 1.56(\mathrm{~m}, 4 \mathrm{H}), 1.85(\mathrm{~m}, 4 \mathrm{H}), 2.17$ (s, 6 $\mathrm{H}, \mathrm{CH}_{3}$ on AcAc group), 3.59 (s, $4 \mathrm{H}, \mathrm{CH}_{2}$ on AcAc group), $4.04(\mathrm{~m}, 4 \mathrm{H}), 4.22$ (t, $2 \mathrm{H}, J=6.8$ $\mathrm{Hz}), 4.34$ (t, $2 \mathrm{H}, J=6.7 \mathrm{~Hz}), 9.22(\mathrm{~s}, 1 \mathrm{H}), 10.10$ (s, $1 \mathrm{H}) .{ }^{13} \mathrm{C}$ NMR (DMSO-d $\left.{ }_{6}\right): \delta 24.66$, 24.99, 25.04, 27.77, 27.92, 28.65, 30.11, 47.42, 49.60, 51.53, 64.24, $120.70\left(J=320 \mathrm{~Hz},-\mathrm{CF}_{3}\right)$, 142.46, 144.64, 167.32, 201.72. Anal. calculated for $\mathrm{C}_{23} \mathrm{H}_{36} \mathrm{~F}_{3} \mathrm{~N}_{3} \mathrm{O}_{9} \mathrm{~S}, \mathrm{C}$ 47.01, H 6.18, N 7.15; found, C 46.98, H 6.14, N 7.25.

2.8 Synthesis of 1,4-bis(6'-acetoacetoxyhexyl)-1,2,4-triazolium bis(trifluoromethylsulfonyl)imide 7

To a $50 \mathrm{~mL}$ round-bottomed flask equipped with a magnetic stir bar was dissolved 1,3bis $(6$-acetoacetoxyhexyl)imidazolium bromide $5(2.50 \mathrm{~g}, 4.83 \mathrm{mmol})$ in DI water $(20 \mathrm{~mL})$. To this stirred solution was added a solution of lithium bis(trifluoromethylsulfonyl)imide (1.46 g, $5.07 \mathrm{mmol})$ in DI water $(5 \mathrm{~mL})$. The mixture was vigorously stirred overnight at room temperature. The organic phase was separated, washed twice with DI water and then the solvent was removed under reduced pressure to afford $3.23 \mathrm{~g}(93 \%)$ of a light yellow oil. ${ }^{1} \mathrm{H}$ NMR $\left(\mathrm{DMSO}-d_{6}\right): \delta 1.32(\mathrm{~m}, 4 \mathrm{H}), 1.57(\mathrm{~m}, 4 \mathrm{H}), 1.84(\mathrm{~m}, 4 \mathrm{H}), 2.17$ (s, $6 \mathrm{H}, \mathrm{CH}_{3}$ on AcAc group), 3.59 (s, $4 \mathrm{H}, \mathrm{CH}_{2}$ on AcAc group), 4.04 (m, $\left.4 \mathrm{H}\right), 4.23$ (t, $\left.2 \mathrm{H}, J=6.7 \mathrm{~Hz}\right), 4.35$ (t, $2 \mathrm{H}, J=6.8$ $\mathrm{Hz}), 9.23(\mathrm{~s}, 1 \mathrm{H}), 10.11(\mathrm{~s}, 1 \mathrm{H}) .{ }^{13} \mathrm{C}$ NMR (DMSO-d $\left.d_{6}\right): \delta 24.63,25.01,25.04,27.76,27.92$, 28.67, 30.12, 47.41, 49.58, 51.52, 64.24, $119.45\left(\mathrm{~J}=316 \mathrm{~Hz},-\mathrm{CF}_{3}\right), 142.41,144.61,167.29$, 201.65. Anal. calculated for $\mathrm{C}_{24} \mathrm{H}_{36} \mathrm{~F}_{6} \mathrm{~N}_{4} \mathrm{O}_{10} \mathrm{~S}_{2}, \mathrm{C} 40.11, \mathrm{H}$ 5.05, N 7.80; found, C 40.09, H 5.01, N 7.93. 


\subsection{Michael addition polymerization procedure}

Due to the incompatibility of acetoacetate monomers $\mathbf{5 , 7}$ and $\mathbf{8}$ with the diacrylate monomer, polymerizations were completed in a solvent. In a typical procedure, 1,3-bis(2'acetoacetoxyethyl)imidazolium bromide $5(0.80 \mathrm{~g}, 1.97 \mathrm{mmol})$ and 1,4-butanediol diacrylate (0.55 g, $2.76 \mathrm{mmol}, 1.4$ molar equiv.) were dissolved in dichloromethane (1.35 g - 50 wt \%). DBU catalyst (27 mg, $2 \mathrm{wt} \%$ ) was then added and the resulting solution was mixed vigorously for two minutes by hand. The solution was then transferred to a Teflon® mold and cured at ambient temperature for $48 \mathrm{~h}$, followed by curing in an oven at $60{ }^{\circ} \mathrm{C}$ for an additional 48 hours. To ensure complete solvent removal, the sample was further placed in a vacuum oven $(<0.1 \mathrm{~mm}$ $\mathrm{Hg}$ ) for 24 hours at $50{ }^{\circ} \mathrm{C}$.

\subsection{Thermal characterization of acetoacetate monomers}

All acetoacetate monomers were stored in a vacuum oven at $40^{\circ} \mathrm{C}$ for $48 \mathrm{hr}$ prior to thermal testing. Differential scanning calorimetry (DSC), with a heating rate of $2^{\circ} \mathrm{C} / \mathrm{min}$ on 5-10 mg samples, was performed using a TA Instrument Q200 Differential Scanning Calorimeter. Glass transition temperatures $\left(T_{g}\right)$ were determined by the inflection point of the curve observed from the second heating cycle. Thermal stabilities were studied under a constant nitrogen flow

using a TA Instrument Q500 Thermogravimetric Analyzer at a heating rate of $10^{\circ} \mathrm{C} / \mathrm{min}$. Onset of thermal decomposition $\left(T_{\text {onset }}\right)$ was determined from the intersection of the tangents of the beginning and sloped portions of the TGA curve. $T_{d 5 \%}$ was determined as the temperature at which $5 \%$ weight loss was observed.

\subsection{Thermal and mechanical characterization of polymer films}

Thermal transitions were found using a TA Instrument Q200 Differential Scanning Calorimeter (DSC) at a heating rate of $2^{\circ} \mathrm{C} / \mathrm{min}$ on 5-10 $\mathrm{mg}$ samples. Glass transition temperatures $\left(T_{g}\right)$ were determined by the inflection point of the curve observed from the second heating cycle. Thermal stabilities, as with the monomers, were studied under a constant nitrogen flow at a heating rate of $10^{\circ} \mathrm{C} / \mathrm{min}$ using a TA Instrument Q500 Thermogravimetric Analyzer. Onset of thermal decomposition $\left(T_{\text {onset }}\right)$ was determined from the intersection of the tangents of the beginning and sloped portions of the TGA curve. $T_{d 5 \%}$ was determined as the temperature at 
which 5\% weight loss was observed. The mechanical properties of the polyester networks were determined using a TA Instruments Q800 Dynamic Mechanical Analyzer (DMA) in film tension mode at a heating rate of $5^{\circ} \mathrm{C} / \mathrm{min}$ with a single frequency of $1 \mathrm{~Hz}$.

\section{Results and Discussion}

\subsection{Synthesis and Thermal Properties of the 1,2,4-Triazolium PILs}

The 1,2,4-triazolium PILs were prepared using the convergent synthetic approach shown in Scheme 2. Substitution of commercially available 1,2,4-triazole was accomplished through the sequential addition of sodium methoxide and ethyl-6-bromohexanoate (note that complete transesterification to the methyl ester also occurred under these conditions). The resulting methyl ester 1 was then reduced using lithium aluminum hydride, followed by reaction with excess tert-butylacetoacetate, providing acetoacetate 3. In a parallel synthesis, 6-bromohexanol was acetoacetylated with excess tert-butylacetatate, resulting in $\mathbf{4}$. The two acetoacetates ( 3 and 4) were then combined and reacted neat at $60{ }^{\circ} \mathrm{C}$ for several days, generating 1,2,4-triazolium diacetoacetate ionic liquid bromide 5. Anion exchange reactions with either silver trifluoromethanesulfonate (AgOTf) or lithium bis(trifluoromethylsulfonyl)imide $\left(\mathrm{LiNTf}_{2}\right)$ provided the corresponding diacetoacetate ionic liquids 6 and 7, respectively. All 1,2,4triazolium PILs were clear, room-temperature ionic liquids with varying degrees of yellow color. Product identification and purity were confirmed by ${ }^{1} \mathrm{H}$ and ${ }^{13} \mathrm{C}$ NMR spectroscopy, as well as elemental analysis, and residual [Br] for PILs 6 and 7 was found to be $<0.1 \%$ w/w by ion chromatography [41]. 


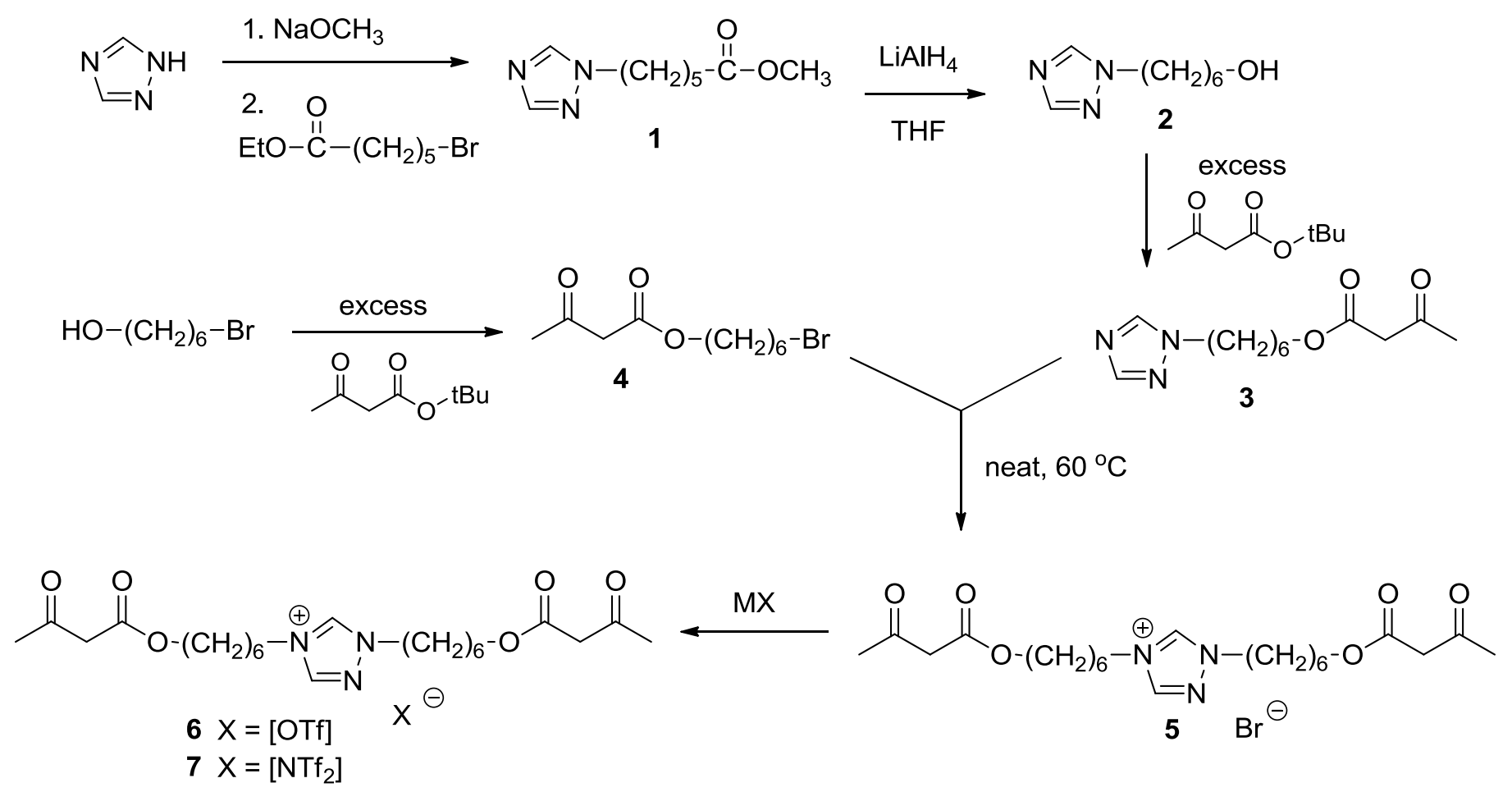

Scheme 2: Preparation of 1,2,4-Triazolium Polymerizable Ionic Liquids 5-7.

Prior to polymerization, the thermal properties of the PILs 5-7 were determined. Glass transition temperatures $\left(T_{g}\right)$ were found using differential scanning calorimetry (DSC) while thermogravimetric analysis (TGA) was utilized to determine thermal stability values (Table 1). Thermal experiments were completed in duplicate with an error of $\pm 2{ }^{\circ} \mathrm{C}$ for all reported values. The PILs were found to exhibit $T_{g}$ values well below room temperature. Of the three PILs studied, [Br] 5 was observed to have the highest $T_{g}$ value $\left(-47.5^{\circ} \mathrm{C}\right)$ while [OTf] 6 and $\left[\mathrm{NTf}_{2}\right] 7$ exhibited $T_{g}$ values below $-56^{\circ} \mathrm{C}$. Larger anions tend to depress the $T_{g}$ of ionic liquids and PILs due to the disruption of ion packing, creating more of a 'quasilattice' arrangement [44].

Comparison of the TGA data indicated that $[\mathrm{Br}] 5$ exhibited the lowest thermal stability, as indicated by both $T_{\text {onset }}$ and $T_{d 5 \%}$, presumably due to the increased Lewis basicity of the bromide anion. Since [OTf] and [ $\left.\mathrm{NTf}_{2}\right]$ are relatively weaker Lewis bases, their observed $T_{d 5} \%$ values were significantly higher $\left(>255^{\circ} \mathrm{C}\right)$ than $[\mathrm{Br}]$. Such a correlation between anion basicity and thermal stability has been previously reported for a number of imidazolium and 1,2,4triazolium ionic liquids $[25,27,45,46]$. 
Table 1: Thermal Properties of 1,2,4-Triazolium-Containing PILs

\begin{tabular}{ccccc}
\hline Compound & Anion & $\begin{array}{c}\text { DSC } T_{g} \\
\left({ }^{\circ} \mathrm{C}\right)\end{array}$ & $\begin{array}{c}\text { TGA } T_{\text {onset }} \\
\left({ }^{\circ} \mathrm{C}\right)\end{array}$ & $\begin{array}{c}\text { TGA } T_{d 5 \%} \\
\left({ }^{\circ} \mathrm{C}\right)\end{array}$ \\
\hline $\mathbf{5}$ & $\mathrm{Br}$ & -47.5 & 213 & 204 \\
$\mathbf{6}$ & OTf & -56.1 & 257 & 240 \\
7 & $\mathrm{NTf}_{2}$ & -61.1 & 277 & 265 \\
\hline
\end{tabular}

\subsection{Polymerization of the 1,2,4-Triazolium PILs and Swelling Studies}

The 1,2,4-triazolium-containing PILs were polymerized by allowing them to react with commercially available 1,4-butanediol diacrylate in the presence of catalytic $2 \mathrm{~mol} \% \mathrm{DBU}$ (Scheme 3) [39,40]. Since the PILs and diacrylate were found to be incompatible, all polymerizations were completed as solutions in dichloromethane (50 wt $\%)$. Once prepared, the polymer solutions were placed into a Teflon ${ }^{\circledR}$ mold and allowed to cure under ambient conditions for 48 hours, then placed into a $60{ }^{\circ} \mathrm{C}$ oven for 48 hours. Finally, to ensure complete curing and removal of trace solvent residue, the polymer films were placed into a vacuum oven at $60{ }^{\circ} \mathrm{C}$ for an additional 48 hours. All of the polymerizations resulted in clear, flexible films with varying degrees of color. 


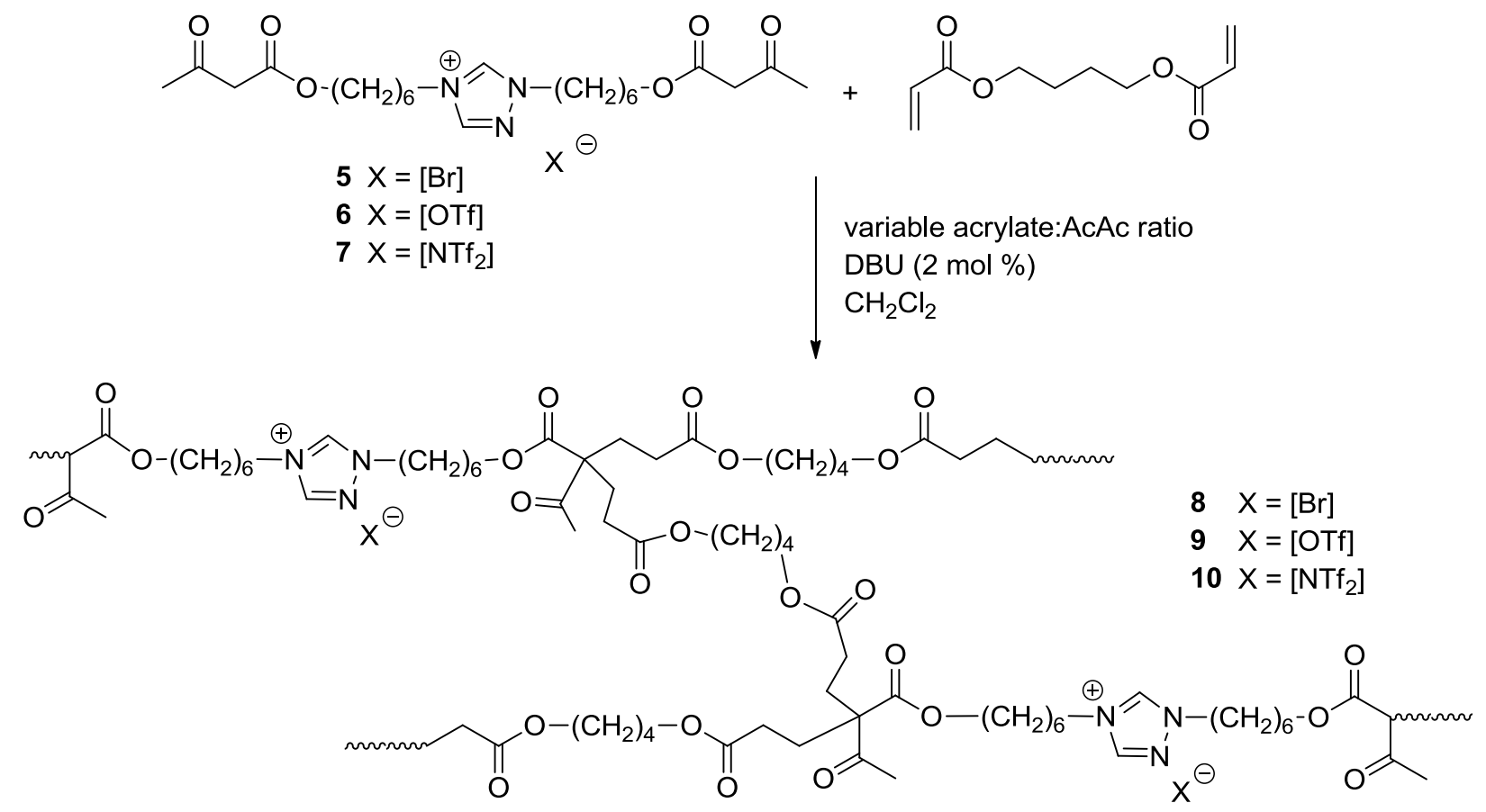

Scheme 3: Preparation of 1,2,4-Triazolium-Containing Polyester Networks 8-10.

The cured polyester networks were initially subjected to Soxhlet extraction using dichloromethane to determine gel fraction and \% swelling (Table 2). A high gel fraction (> 95 $\%)$ was observed for all networks, regardless of anion choice or monomer ratio used. Analysis of the swelling data indicated that use of a larger anion (polymers [OTf] 9 and $\left[\mathrm{NTf}_{2}\right]$ 10) resulted in higher swelling values, presumably due to poorer ion packing within the network. As expected, an increase in the acrylate concentration (polymers 10a-e) decreased the \% swelling of the $\left[\mathrm{NTf}_{2}\right]$-containing polyester networks due to the increase in covalent crosslinking. 
Table 2: Thermal and Swelling Properties of 1,2,4-Triazolium-Containing Polyester Networks

\begin{tabular}{cccccccc}
\hline Polymer & Anion & $\begin{array}{c}\text { Acr:AcAc } \\
\text { Ratio }\end{array}$ & $\begin{array}{c}\text { DSC } \\
T_{g}\left({ }^{\circ} \mathrm{C}\right)\end{array}$ & $\begin{array}{c}\text { TGA } \\
T_{\text {onset }}\left({ }^{\circ} \mathrm{C}\right)\end{array}$ & $\begin{array}{c}\text { TGA } \\
T_{d 5}\left({ }^{\circ} \mathrm{C}\right)\end{array}$ & Gel Fraction & $\%$ Swelling \\
\hline $\mathbf{8}$ & $\mathrm{Br}$ & $1.4: 1.0$ & 3.2 & 219 & 215 & $95.3 \pm 0.7 \%$ & $188 \pm 5 \%$ \\
$\mathbf{9}$ & $\mathrm{OTf}$ & $1.4: 1.0$ & -15.3 & 317 & 296 & $97.0 \pm 0.4 \%$ & $232 \pm 2 \%$ \\
$\mathbf{1 0 a}$ & $\mathrm{NTf}_{2}$ & $1.2: 1.0$ & -22.6 & 328 & 306 & $95.7 \pm 0.9 \%$ & $246 \pm 2 \%$ \\
$\mathbf{1 0 b}$ & $\mathrm{NTf}_{2}$ & $1.4: 1.0$ & -12.6 & 332 & 311 & $97.4 \pm 0.8 \%$ & $229 \pm 5 \%$ \\
$\mathbf{1 0 c}$ & $\mathrm{NTf}_{2}$ & $1.6: 1.0$ & -4.5 & 334 & 318 & $97.6 \pm 0.5 \%$ & $215 \pm 2 \%$ \\
$\mathbf{1 0 d}$ & $\mathrm{NTf}_{2}$ & $1.8: 1.0$ & 4.5 & 335 & 325 & $97.0 \pm 0.5 \%$ & $204 \pm 3 \%$ \\
$\mathbf{1 0 e}$ & $\mathrm{NTf}_{2}$ & $2.0: 1.0$ & 10.8 & 338 & 334 & $95.8 \pm 0.7 \%$ & $189 \pm 5 \%$ \\
\hline
\end{tabular}

\subsection{Thermal Properties of the 1,2,4-Triazolium-Containing Polyester Networks}

The polymer networks were next analyzed by DSC to evaluate $T_{g}$ and thermal stabilities $\left(T_{d 5 \%}\right)$ were determined using TGA (Table 2). All thermal measurements were completed in duplicate with an error of $\pm 2{ }^{\circ} \mathrm{C}$. In general, the polyester networks were found to exhibit higher $T_{g}$ and $T_{d 5 \%}$ values than their corresponding monomers. The network which employed the [Br] anion (polymer 8) was observed to have the highest $T_{g}$ (given the same monomer ratio), presumably due to a closer packing arrangement that exists with the use of a smaller, more highly coordinating anion. Lower $T_{g}$ values were observed for polymers $\mathbf{9}$ and $\mathbf{1 0}$ where the larger [OTf] and $\left[\mathrm{NTf}_{2}\right]$ anions were employed. The correlation between anion size (network packing) and $T_{g}$ is supported by work previously published by our group as well as by Gibson and could be the result of plasticization and/or ionic interactions [41,42,47]. As expected, an increase in acrylate concentration resulted in an increase in $T_{g}$ for the polymer series 10a-e due to the generation of a more highly crosslinked network. For example, the highest $T_{g}\left(10.8{ }^{\circ} \mathrm{C}\right)$ was observed when a 2.0:1.0 acrylate to acetoacetate ratio was employed for polymer 10e.

Analysis of the relative thermal stability values $\left(T_{\text {onset }}\right.$ and $\left.T_{d 5 \%}\right)$, as determined by TGA, once again indicated the important role that Lewis basicity plays in ionic liquids and ionic liquidcontaining polymers. Overall, [Br] 8 was observed to have a significantly lower $T_{d 5 \%}$ value (215 ${ }^{\circ} \mathrm{C}$ ) than either 9 [OTf] or $\mathbf{1 0}\left[\mathrm{NTf}_{2}\right]\left(296{ }^{\circ} \mathrm{C}\right.$ and $311{ }^{\circ} \mathrm{C}$, respectively) given the same acrylate to 
acetoacetate ratio. On the other hand, increasing the apparent crosslink density across the polymer series 10a-e resulted in a gradual increase in thermal stability, with the 2.0:1.0 acrylate:acetoacetate system exhibiting a $T_{d 5 \%}$ value of $334{ }^{\circ} \mathrm{C}$. All of the trends observed from DSC and TGA analysis are in alignment with previously published work on analogous imidazolium and non-ionic Michael addition polyester networks [39,41].

\subsection{Mechanical Properties of the 1,2,4-Triazolium-Containing Polyester Networks}

Dynamic Mechanical Analysis (DMA) was used to characterize the mechanical properties of the 1,2,4-triazolium-containing polyester networks. Important network properties such as DMA $T_{g}$, apparent crosslink density $\left(\rho_{\mathrm{x}}\right)$ and the molecular weight between crosslinks $\left(M_{c}\right)$ can be determined using DMA as demonstrated in a number of previously published articles [39,48-50]. Glass transition $\left(T_{g}\right)$ values were determined from the maximum of the tan $\delta$ curve for each network while the apparent crosslink density and $M_{c}$ values were calculated from the rubbery plateau region of the storage modulus $\left(E^{\prime}\right)$ curve above the $T_{g}$.

The networks which employed different anions, given a constant 1.4:1.0 acrylate to acetoacetate ratio, were compared initially (Figure 1). It was observed that polyester network $\mathbf{8}$, which incorporated the $[\mathrm{Br}]$ anion (a more tightly packed network), provided the highest rubbery plateau modulus as well as the highest DMA $T_{g}$ value (Table 3) while use of the bulkier, noncoordinating [OTf] and $\left[\mathrm{NTf}_{2}\right]$ anions resulted in lower $E^{\prime}$ and $T_{g}$ values. This correlation between counteranion and $E^{\prime}$ (and $T_{g}$ ) could be the result of plasticization and/or ionic interactions, however no attempts were made to decouple these effects as part of this study. It is also worth noting that the $[\mathrm{Br}]$ network began to lose its mechanical stability as it passed its chemical degradation limit $\left(\mathrm{T}_{\mathrm{d} 5 \%}=215^{\circ} \mathrm{C}\right)$. 


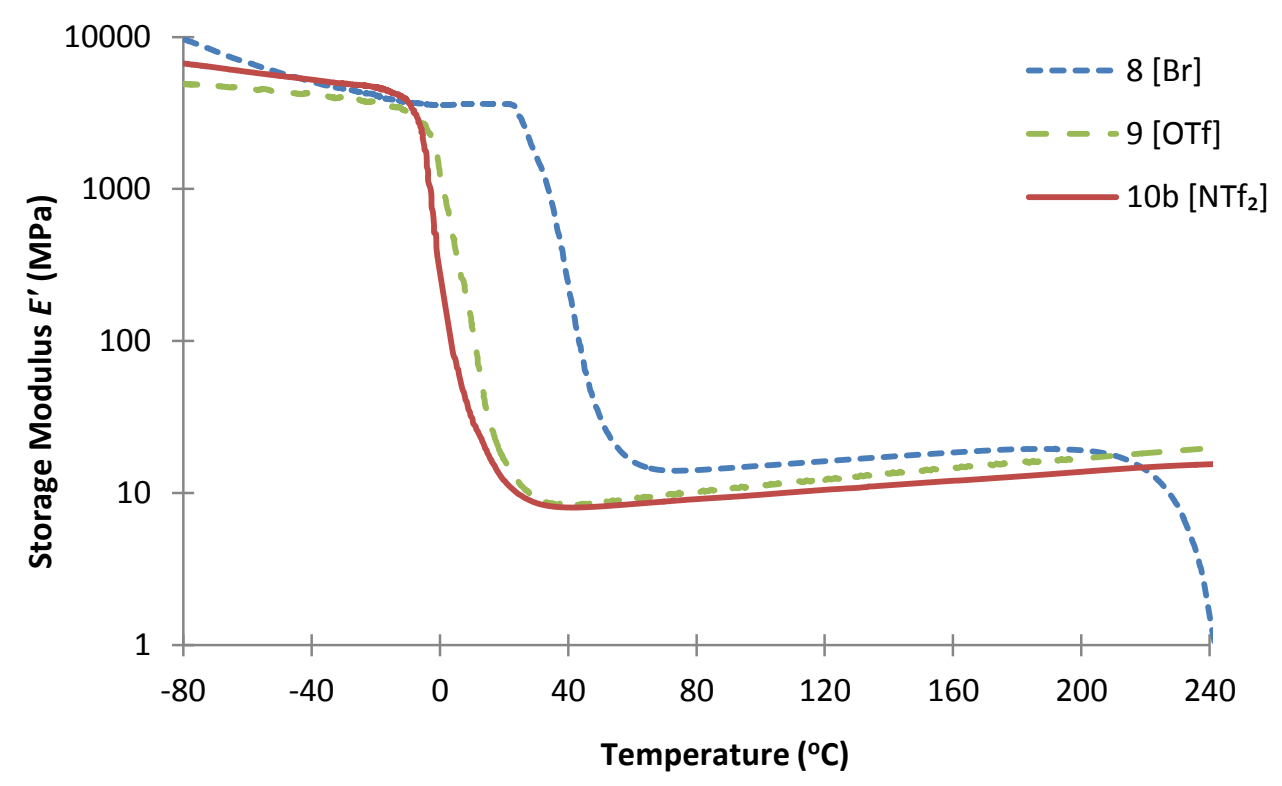

Figure 1: DMA Storage Modulus (E') Comparison with Anion Variation

Crosslink density $\left(\rho_{\mathrm{x}}\right)$ is one of many important structural features that define the thermal and mechanical properties of polymer networks. Previously published work has shown the influence of monomer molecular weight and acrylate to acetoacetate ratio on the apparent crosslink density of non-ionic polyester networks prepared by Michael addition polymerization [39]. Thus, it was of interest to explore this same property for the present 1,2,4-triazoliumcontaining systems. From the theory of rubbery elasticity, the crosslink density $\left(\rho_{x}\right)$ of a polyester network can be determined by:

$$
\rho_{x}=E^{\prime} / 3 R T
$$

where $E^{\prime}$ is the storage modulus at a temperature above the $\mathrm{T}_{\mathrm{g}}(\mathrm{Pa}), R$ is the gas constant $(8.314$ $\mathrm{J} \cdot \mathrm{mol} / \mathrm{K})$ and $T$ is the temperature $(\mathrm{K})$ [39,49,51-53]. Calculated results are provided in Table 3. It was observed that, given the same 1.4:1.0 acrylate to acetoacetate ratio, $\rho_{x}$ appears to correlate in the order of $\left[\mathrm{NTf}_{2}\right]<[\mathrm{OTf}]<[\mathrm{Br}]$ within the anion series, with use of $[\mathrm{Br}]$ resulting in the highest value $\left(1.63 \times 10^{-3} \mathrm{~mol} / \mathrm{cm}^{3}\right)$. As with $E^{\prime}$, the relationship between counternion and $\rho_{x}$ could be the result of plasticization and/or ionic interactions within the networks. 
Table 3: Mechanical Properties of 1,2,4-Triazolium-Containing Polyester Networks

\begin{tabular}{ccccccc}
\hline Polymer & Anion & $\begin{array}{c}\text { Acr:AcAc } \\
\text { Ratio }\end{array}$ & $\begin{array}{c}\operatorname{Tan} \delta \mathrm{Max} \\
T_{g}\left({ }^{\circ} \mathrm{C}\right)\end{array}$ & $\begin{array}{c}E^{\prime} @ 100{ }^{\circ} \mathrm{C} \\
(\mathrm{MPa})\end{array}$ & $\begin{array}{c}\rho_{\mathrm{x}} \times 10^{-3} \\
\left(\mathrm{~mol} / \mathrm{cm}^{3}\right)\end{array}$ & $\begin{array}{c}M_{c} \\
(\mathrm{~g} / \mathrm{mol})\end{array}$ \\
\hline $\mathbf{8}$ & $\mathrm{Br}$ & $1.4: 1.0$ & 24.5 & 15.16 & 1.63 & 829 \\
$\mathbf{9}$ & OTf & $1.4: 1.0$ & 8.8 & 11.21 & 1.20 & 1063 \\
$\mathbf{1 0 a}$ & $\mathrm{NTf}_{2}$ & $1.2: 1.0$ & -13.2 & 8.37 & 0.90 & 1357 \\
$\mathbf{1 0 c}$ & $\mathrm{NTf}_{2}$ & $1.4: 1.0$ & 3.3 & 9.78 & 1.05 & 1170 \\
$\mathbf{1 0 d}$ & $\mathrm{NTf}_{2}$ & $1.6: 1.0$ & 12.5 & 13.61 & 1.45 & 862 \\
$\mathbf{1 0 e}$ & $\mathrm{NTf}_{2}$ & $1.8: 1.0$ & 23.1 & 17.51 & 1.88 & 659 \\
\hline
\end{tabular}

The molecular weight between crosslinks $\left(M_{c}\right)$ can be calculated from the rubbery plateau region of the storage modulus curve according to the following equation:

$$
M_{c}=3 \rho R T / E^{\prime}
$$

where $\rho$ is the polymer density $\left(\mathrm{g} / \mathrm{cm}^{3}\right)$. The resulting $M_{c}$ values are provided in Table 3 . The $M_{c}$ values increase accordingly with increasing molecular weight of the anion with the $\left[\mathrm{NTf}_{2}\right]$ containing network $\mathbf{1 0 b}$ exhibiting the highest $M_{c}$ value of $1170 \mathrm{~g} / \mathrm{mol}$.

Focus was next turned to networks in which the acrylate to acetoacetate monomer ratio was varied, given a constant anion $\left[\mathrm{NTf}_{2}\right]$ (polymers 10a-e). As expected, an increase in the acrylate concentration led to an increase in the rubbery plateau modulus (Figure 2) as well as a linear increase in DMA $T_{g}$ as determined from the peaks of the $\tan \delta$ curves (Figure $3 ; \mathrm{r}^{2}=$ 0.992). It is worth noting that an analogous linear correlation was found between DSC $T_{g}$ and monomer ratio $\left(\mathrm{r}^{2}=0.995\right)$, indicating that covalent crosslinking can be controlled sequentially by increasing the acrylate concentration. The lowest plateau modulus $\left(8.37 \mathrm{MPa}\right.$ at $\left.100{ }^{\circ} \mathrm{C}\right)$ and $\tan \delta$ maximum $\left(-13.2{ }^{\circ} \mathrm{C}\right)$ value were observed for the 1.2:1.0 acrylate to acetoacetate network 10a while the highest modulus $\left(22.44 \mathrm{MPa}\right.$ at $\left.100{ }^{\circ} \mathrm{C}\right)$ and $\tan \delta$ maximum $\left(36.6{ }^{\circ} \mathrm{C}\right)$ resulted 
from polymer 10e, which employed a 2.0:1.0 acrylate to acetoacetate ratio. A numerical summary of the DMA data for these systems is provided in Table 3.

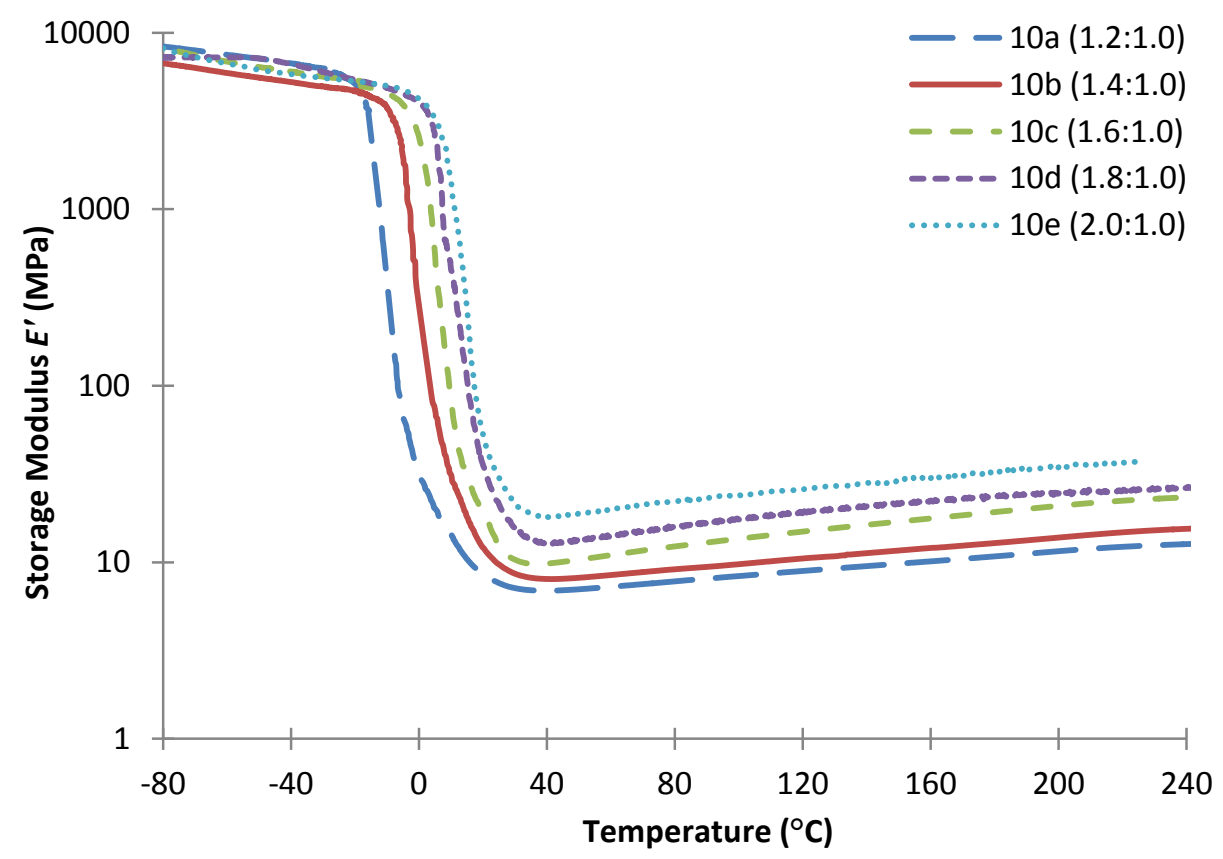

Figure 2: DMA Storage Modulus (E') Comparison with Variable Acrylate Concentration

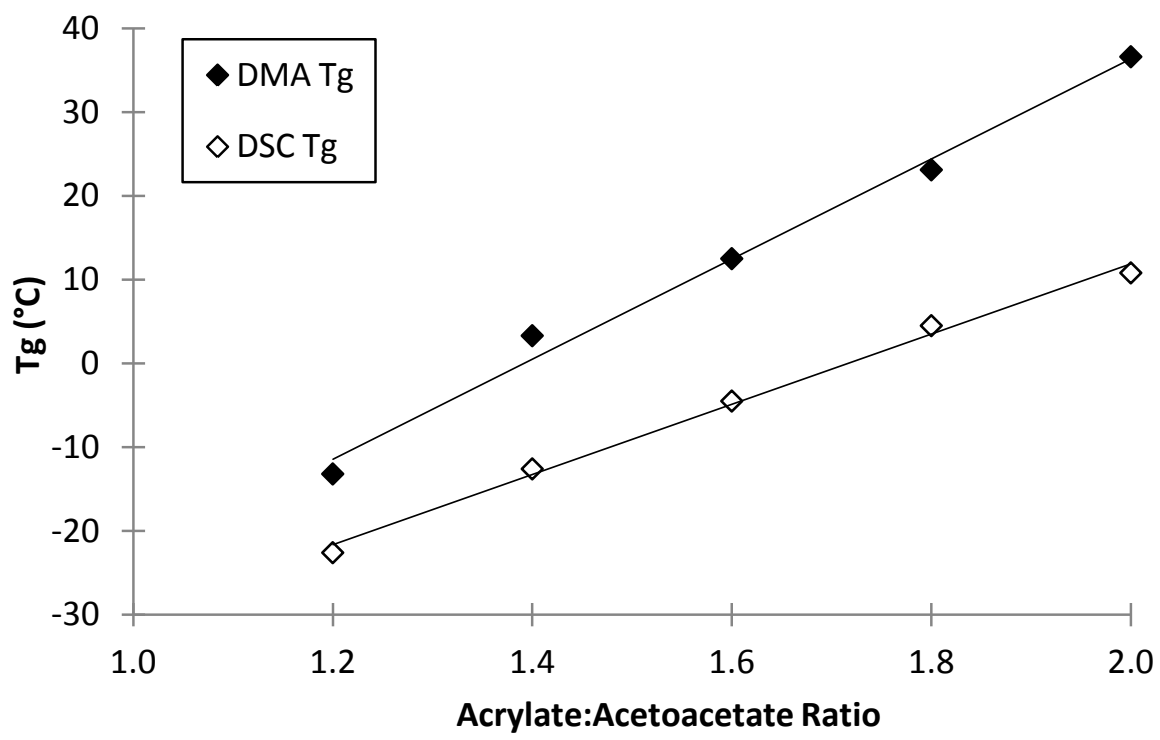

Figure 3: $T_{g}$ Correlation with Variable Acrylate Concentration 
Apparent crosslink density $\left(\rho_{\mathrm{x}}\right)$ and $M_{c}$ values, which were calculated according to Equations (1) and (2), respectively, are also included in Table 3. Apparent crosslink density was observed to increase with acrylate to acetoacetate ratio (Figure 4), where the highest value (2.41 x $10^{-3} \mathrm{~mol} / \mathrm{cm}^{3}$ ) was exhibited by the 2.0:1.0 acrylate to acetoacetate ratio. Likewise, $M_{c}$ values were found to decrease with increasing acrylate concentration. Both trends clearly point to a correlation between acrylate concentration and covalent crosslinks within the network and support the use of Michael addition technology as a viable and tunable platform for the formation of IL-containing polyester networks.

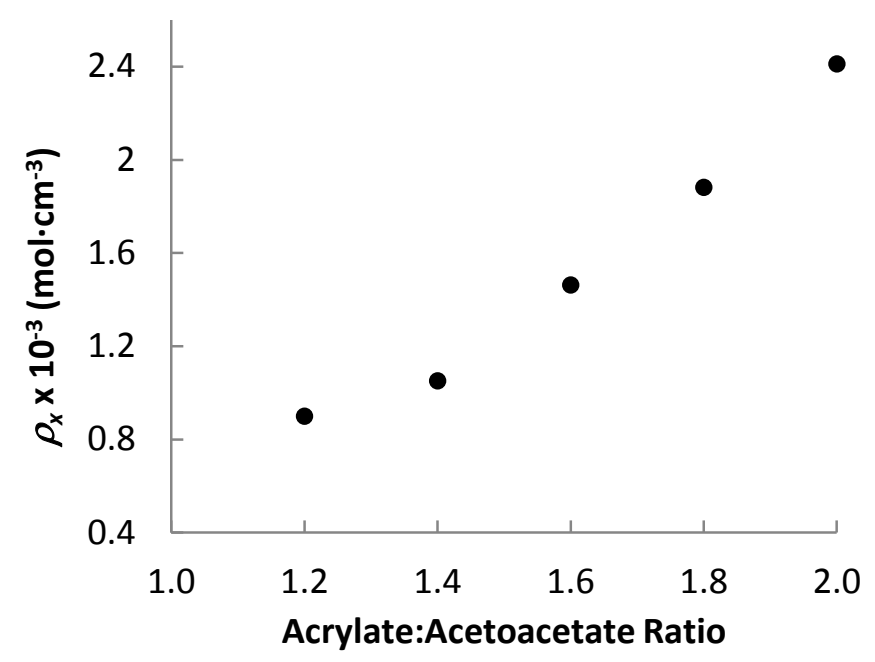

Figure 4: Correlation between Apparent crosslink density and Acrylate Concentration

\subsection{Comparison with Analogous Imidazolium-Containing Network}

The thermal and mechanical properties of the 1,2,4-triazolium-cotaining polyester network 10b was next compared to the analogous imidazolium [ $\left.\mathrm{NTf}_{2}\right]$-containing network. Towards this end, a freshly prepared network sample utilizing monomer 11 (Figure 5) at a 1.4:1.0 acrylate to acetoacetate ratio was prepared and cured in the same manner as previously described. Thermal analysis of the imidazolium-containing network revealed that the polymer exhibited a slightly lower $T_{g}\left(-18.2^{\circ} \mathrm{C}\right)$ than the corresponding 1,2,4-triazolium-based polymer 10b $\left(-12.6{ }^{\circ} \mathrm{C}\right)$ while the $T_{d 5 \%}$ values, as determined by TGA, were within experimental error (Table 4). It could be argued that the increased Lewis acidity of the 1,2,4-triazolium ring might 
led to stronger cation-anion bonding within the polymer network, thus leading to the small observed increase in the $T_{g}[54,55]$.

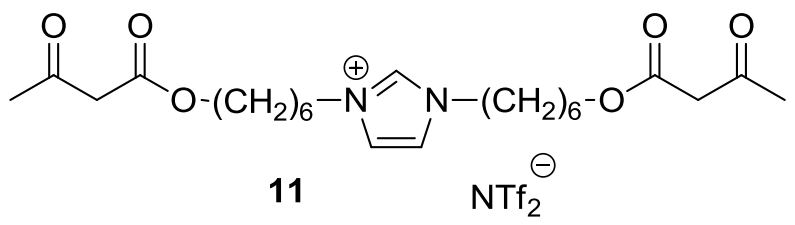

Figure 5: Imidazolium-Containing Acetoacetate Monomer 11

Table 4: Thermal and Mechanical Properties of an Imidazolium [NTf 2 ]-Containing Polyester Network using a 1.4:1.0 Acrylate to Acetoacetate Ratio

\begin{tabular}{cccccc}
\hline $\begin{array}{c}\mathrm{DSC} \\
T_{g}\left({ }^{\circ} \mathrm{C}\right)\end{array}$ & $\begin{array}{c}\mathrm{TGA} \\
T_{d 5 \%}\left({ }^{\circ} \mathrm{C}\right)\end{array}$ & $\begin{array}{c}\text { Tan } \delta \mathrm{Max} \\
T_{g}\left({ }^{\circ} \mathrm{C}\right)\end{array}$ & $\begin{array}{c}E^{\prime} @ 100{ }^{\circ} \mathrm{C} \\
(\mathrm{MPa})\end{array}$ & $\begin{array}{c}\rho_{\mathrm{x} \times ~} 10^{-3} \\
\left(\mathrm{~mol} / \mathrm{cm}^{3}\right)\end{array}$ & $\begin{array}{c}M_{c} \\
(\mathrm{~g} / \mathrm{mol})\end{array}$ \\
\hline-18.2 & 310 & 5.5 & 10.15 & 1.09 & 1155 \\
\hline
\end{tabular}

Analysis of the mechanical properties of the imidazolium-based polyester network revealed that there was very little difference in the rubbery plateau storage modulus $\left(E^{\prime}=10.15\right.$ $\mathrm{MPa}$ ) in comparison to 1,2,4-triazolium-containing polymer $10 \mathbf{b}$ (9.78 MPa). Apparent crosslink density $\left(\rho_{\mathrm{x}}\right)$ and $M_{c}$, as determined from Equations (1) and (2), respectively, confirmed the similarities between the two networks in terms of their mechanical properties.

\section{Conclusions}

In summary, a series of 1,2,4-triazolium-based bisacetoacetate monomers were prepared and polymerized using Michael addition technology. The resulting covalently crosslinked polyester networks were analyzed for their thermal (DSC, TGA) and mechanical (DMA) properties. Two structural variables were investigated as part of this study: the acrylate to acetoacetate ratio and the counteranion.

Thermal analysis of the 1,2,4-triazolium-containing networks indicated a gradual increase in the glass transition temperature $\left(T_{g}\right)$ when the acrylate concentration was increased, presumably due to an increase in covalent crosslinking within the network. An increase in thermal stability $\left(T_{d 5 \%}\right)$ was also observed as a result of increasing the acrylate concentration. 
Use of larger, non-coordinating anions such as triflate [OTf] or bis(trifluoromethylsulfonyl)imide [NTf 2 led to a decrease in $T_{g}$ but an increase in $\mathrm{T}_{\mathrm{d} 5 \%}\left(>295^{\circ} \mathrm{C}\right)$.

Dynamic mechanical analysis indicated an increase in the rubbery plateau storage modulus $\left(E^{\prime}\right)$ as well as apparent crosslink density $\left(\rho_{x}\right)$ as a result of increased acrylate concentration, with the 2.0:1.0 acrylate to acetoacetate network exhibiting the highest observed $E^{\prime}$ value of $22.44 \mathrm{MPa}$ at $100{ }^{\circ} \mathrm{C}$. As expected, the molecular weight between crosslink points $\left(M_{c}\right)$ decreased as acrylate concentration and apparent crosslink density increased. Incorporation of the [OTf] or $\left[\mathrm{NTf}_{2}\right]$ anion led to decrease in the $E^{\prime}$ at $100{ }^{\circ} \mathrm{C}$ when compared with the [Br] anion apparently due to the tighter network packing that exists from using a smaller, more strongly coordinating anion. Overall, the 1,2,4-triazolium-based network with an acrylate:acetoacetate ratio of 1.4:1.0 was comparable with respect to its thermal and mechanical properties to the analogous imidazolium network.

\section{Acknowledgements}

Acknowledgement is made to the donors of the American Chemical Society Petroleum Research Fund for support of this research (ACS PRF\# 53097-UNI7). Thermal and mechanical analyses were conducted in the Polymer and Materials Science Laboratory (PMCL) at Murray State University. DMA support was provided by the Department of Chemistry at Murray State University as a result of support from the National Science Foundation (Major Research Instrumentation) under DMR-1427778.

\section{References}

[1] Welton T. Chem. Rev. 1999; 99(8): 2071-2084.

[2] Wasserscheid P, Keim W. Agnew. Chem., Int. Ed. 2000;39(21): 3772-3789. 
[3] Rogers, RD, editor. Ionic Liquids IIIA: Fundamentals, Challenges and Opportunities, ACS symposium series 901. Washington, D.C.: American Chemical Society, 2005.

[4] Plechkova, NV, Seddon, KR. Chem. Soc. Rev. 2008; 37(1): 123-150.

[5] Ohno H, Ito K. Chem. Lett 1998; 27(8): 751-752.

[6] Nishimura N, Ohno H. Polymer 2014; 55(16): 3289-3297.

[7] Green MD, Long TE. J Macro Sci Part C Polym Rev 2009; 49(4): 291-314.

[8] Green O, Grubjesic S, Lee S, Firestone MA. Polym Rev 2009; 49(4): 339-360.

[9] Yuan J, Mecerreyes D, Antonetti M. Prog Polym Sci 2013; 38 (7): 1009-1036.

[10] Yuan J; Antonietti M. Polymer 2014; 52(7): 1469-1482.

[11] Mecerreyes D. Prog Polym Sci 2011; 36(12): 1629-1648.

[12] Lee M, Choi UH, Colby RH, Gibson HW. Chem Mater 2010; 22(21): 5814-5822.

[13] Chen H, Elbad YA. Macromolecules 2009; 42(9): 3368-3373.

[14] OgiharaW, Washiro S, Nakajima H, Ohno H. Electrochem Acta 2006; 51: 2614-2619.

[15] Bara JE, Lessmann S, Gabriel CJ, Hatakeyama ES, Noble RD, Gin DL. Ind Eng Chem Res 2007; 46(16): 5397-5404.

[16] Tomé LC, Gouveia ASL, Freire CSR, Mecerreyes D. J Membr Sci 2015; 486: 40-48.

[17] Charan KTP, Pothanagandhi N, Vijayakrishna K, Sivaranakrishna A, Mecerreyes D, Sreedhar B. Eur Polym J 2014; 60: 114-122.

[18] Ang HG, editor. Energetic Polymers: Binders and Plasticizers for Enhancing Performance. Wiley-VCH: New York, 2012.

[19] Drake G, Hawkins T, Brand A, Hall L, McKay M, Vij A, Ismail I. Propellants Explos Pyrotech 2003; 28: 174-180.

[20] Zhang Q, Shreeve JM. Chem Rev 2014; 114(20): 10527-10574. 
[21] Singh RP, Verma RD, Meshri DT, Shreeve JM. Angew Chem Int Ed 2006; 45(22): 35843601.

[22] Gao Y, Gao H, Piekarsji C, Shreeve JM. Eur J Inorg Chem 2007: 4965-4972.

[23] Xue H, Gao B, Twamley B, Shreeve JM. Chem Mater 2005; 17(1): 191-198.

[24] McCrary PD, Chatel G, Alaniz SA, Cojocaru OA, Beasley PA, Flores LA, Kelley SP, Barber PS, Rogers RD. Energy Fuels 2014; 28(5): 3460-3473.

[25] Daily LA, Miller KM. J Org Chem 2013; 78(8): 4196-4201.

[26] De La Hoz AT, Brauer UG, Miller KM. J Phys Chem B 2014; 118(33): 9944-9951.

[27] Brauer UG, De La Hoz AT, Miller KM. J Mol Liq 2015;

http://dx.doi.org/10.1016/j.molliq.2015.02.041.

[28] Rostovtsev VV, Green LG, Folkin VV, Sharpless KB. Angew Chem Int Ed 2002; 41(14) 2596-2599.

[29] Iha RK, Wooley KL, Nystrom AM, Burke DJ, Kade MJ, Hawker CJ. Chem Rev 2009; 109(11): 5620-5686.

[30] Beghdadi S, Abdelhedi MI, Addis D, Ben Romdhane H, Bernard J, Drockenmuller E. Polym Chem 2012; 3(4): 1680-1692.

[31] Sumerlin BS, Vogt AP. Macromolecules 2010; 43(1): 1-13.

[32] Sood R, Obadia MM, Mudraboyina BP, Zhang B, Serghei A, Drockenmuller E. Polymer 2014; 55(16): 3314-3319.

[33] Adzima BJ, Taylor SC, He H, Luebke DR, Matyjaszewski K, Nulwala HB. J Polym Sci A: Polym Chem 2014; 52(3): 417-423.

[34] Dmitrov RP, Beghdadi S, Serghei A, Drockenmuller E. J Polym Sci A: Polym Chem 2013; 51(1): 34-38.

[35] Mudraboyina BP, Obadia MM, Allaoua I, Sood R, Serghei A, Drockenmuller E.; Chem 
Mater 2014; 26(4): 1720-1726.

[36] Mudraboyina BP, Obadia MM, Abedelhedi-Miladi I, Allaoua I, Drockenmuller E. Eur Polym J 2015; 62: 331-337.

[37] Xue H, Gao H, Shreeve JM. J Polym Sci A: Polym Chem 2008; 46: 2414.2421.

[38] Mather BD, Viswanathan K, Miller KM, Long TE. Prog Polym Sci 2006; 31 (5): 487-531.

[39] Mather BD, Miller KM, Long TE. Macromol Chem Phys 2006; 207 (15): 1324-1333.

[40] Williams SR, Miller KM, Long TE. Prog React Kinet Mec 2007; 32 (4): 165-194.

[41] Kim S, Miller KM. Polymer 2012; 53(25): 5666-5674.

[42] Whittington CP, Daily LA, Miller KM. Polymer 2014; 55(16): 3320-3329.

[43] Snelling R, Saavedra JZ, Bayrasy P, Abdollahian Y, Singaram B. Org Chem Front 2015; 2(2): 133-140.

[44] Angell CA, Ansari Y, Zhao Z. Faraday Discuss 2012; 154: 9-27.

[45] Tokuda H, Hayamizu K, Ishii K, Susan MABH, Watanabe M. J Phys Chem B 2004; 108(42): 16593-16600.

[46] Tokuda H, Tsuzuki S, Susan MABH, Hayamizu K, Watanabe M. J Phys Chem B 2006; 110(39): 19593-19600.

[47] Lee M, Choi UH, Salas-de la Cruz D, Mittal A, Winey KI, Colby RH, Gibson HW. Adv Funct Mater 2011; 21: 708-717.

[48] Anseth KS, Bowman CN, Peppas NA. Polym Bull 1993; 31: 229-233.

[49] Pavlinec J, Moszner N. J Appl Polym Sci 1997; 65(1): 165-178.

[50] Gorsche C, Griesser M, Gescheidt G, Moszner N, Liska R. Macromolecules 2014; 47(21): 7327-7336.

[51] Calvet D, Wong JY, Giasson S. Macromolecules 2004; 37(20): 7762-7771. 
[52] Fischer M. Adv Polym Sci 1992; 100:313-355.

[53] Flory PJ. Principles of Polymer Chemistry. Cornell University Press: Ithaca, 1953.

[54] Massey RS, Collett CJ, Lindsay AG, Smith AD, O’Donoghue AC. J Am Chem Soc 2012; 134(50): 20421-20432.

[55] Alder RW, Allen PR, Williams SJ. J Chem Soc Chem Commun 1995; 12: 1267-1268. 